\title{
Parathyroid cyst eclipsed by parathyroid adenoma: Value of adjunct imaging
}

\section{Khyati Bhatia, Deepak Sarin¹, Gopal Kumar Singh¹, Alka Ashmita Singhal²}

Departments of ENT and Head and Neck Surgery, ${ }^{1} \mathrm{Head}$ and Neck Oncosurgery and ${ }^{2}$ Radiology and Nuclear Imaging, Medanta, The Medicity, Gurgaon, Haryana, India

Correspondence: Dr. Khyati Bhatia, 8/6, Second Floor, South Patel Nagar, New Delhi-110 008, India. E-mail: khyati222@gmail.com

\begin{abstract}
Parathyroid cyst is a rare clinical entity and often presents as a diagnostic challenge, especially when presents in conjunction with a coexistent parathyroid adenoma. Patient with primary hyperparathyroidism had presented with a localised left inferior parathyroid adenoma with a coexistent right inferior parathyroid cyst which was initially missed on routine ultrasound and sestamibi scan. Suspicion of right inferior thyroid cyst was raised on ultrasound done by a dedicated parathyroid ultrasonologist. Right inferior thyroid cyst was confirmed to be parathyroid cyst on histopathological examination. Parathyroid cysts are seldom picked on sestamibi due to compressed parathyroid tissue present only at the periphery of the cyst. Hence, use of adjunct anatomical imaging like ultrasound, CT scan or MRI is worthwhile to reduce chances of missing hyperfunctional parathyroid tissue, which can eventually lead to revision surgery for persistent primary hyperparathyroidism.
\end{abstract}

Key words: Parathyroid adenoma; parathyroid cyst; sestamibi; ultrasound

\section{Introduction}

Parathyroid cysts are one of the rare causes of cystic mass in the neck. Parathyroid cysts represent $0.5-1 \%$ of parathyroid lesions and $<1 \%$ of neck mass. ${ }^{[1]}$ These were described by Swedish anatomist Sandstorm in 1880 for the first time in literature and about 300 cases have been reported in the literature so far. ${ }^{[2]}$ These cysts can be divided into functional cysts and non-functional cysts.

Functional cysts are generally associated with signs and symptoms of primary hyperparathyroidism whereas, non-functional cysts are mostly asymptomatic, are not associated with hyperparathyroidism and are generally detected as an incidental finding during thyroid or cervical investigations. ${ }^{[3]}$ We present a case report of a parathyroid cyst coexistent with a parathyroid adenoma. This is a

\begin{tabular}{|l|l|}
\hline \multicolumn{2}{|c|}{ Access this article online } \\
\hline Quick Response Code: & \\
\cline { 1 - 2 } & Website: \\
\hline & www.ijri.org \\
\hline & DOI: \\
\hline
\end{tabular}

unique scenario as the hyperparathyroidism in this case was attributable to parathyroid adenoma and the parathyroid cyst was detected as an incidental finding, though the functional status of the cyst remains a question mark in our report.

\section{Case History}

A 65-year-old gentleman was referred to us by the endocrinologist for parathyroidectomy. He had presented to the hospital with a history of recurrent kidney stones and was being investigated for the same. During the course of investigations he was found to have hypercalcemia and hyperparathyroidism. On retrospective probing, he also

This is an open access journal, and articles are distributed under the terms of the Creative Commons Attribution-NonCommercial-ShareAlike 4.0 License, which allows others to remix, tweak, and build upon the work non-commercially, as long as appropriate credit is given and the new creations are licensed under the identical terms.

For reprints contact: WKHLRPMedknow_reprints@wolterskluwer.com

Cite this article as: Bhatia K, Sarin D, Singh GK, Singhal AA. Parathyroid cyst eclipsed by parathyroid adenoma: Value of adjunct imaging. Indian J Radiol Imaging 2020;30:524-8.

Received: 18-Nov-2019 Accepted: 01-Sep-2020

Revised: 03-Feb-2020 Published: 13-Jan-2021 
had history of excessive fatigue and decreased stamina for last one year. His serum calcium was found to be higher than $12.5 \mathrm{mg} / \mathrm{dl}$ on all occasions. His Parathormone (PTH) levels were found to be elevated in the range of 130 and $140 \mathrm{pg} / \mathrm{ml}$, serum 25 dihydroxy vitamin D levels were $10.4 \mathrm{ng} / \mathrm{ml}$, serum creatinine was $1.97 \mathrm{mg} \%$ and 24 hours urinary calcium and creatinine were in the normal range.

A diagnosis of primary hyperparathyroidism was made and patient was investigated further. Ultrasound of the neck, done elsewhere, was suggestive of left inferior parathyroid adenoma with no other abnormal findings in the neck. Double-phase parathyroid scintigraphy with technetium $99 \mathrm{~m}(99 \mathrm{mTc})$-sestamethoxyisobutylisonitrile (Sestamibi) was done which was suggestive of parathyroid adenoma situated inferior to the lower pole of left thyroid gland with no other areas of uptake [Figure 1]. An ultrasound of the neck was repeated in our centre by a dedicated parathyroid ultrasonologist. The repeat ultrasound confirmed a well-defined, ovoid, hypoechoic lesion $14 \times 8 \times 13 \mathrm{~mm}$ inferior to the inferior pole of left thyroid gland [Figure 2]. There was an incidental pick up of hypoechoic, well defined, ovoid cystic nodule measuring $11 \times 8 \times 5 \mathrm{~mm}$ below the lower pole of right thyroid gland [Figure 3]. This cystic nodule was presumed to be thyroidal in origin though the appearance was not classical of a thyroid cyst. Since the patient was planned for a left inferior parathyroidectomy, a decision was taken to explore the cyst intraoperatively and further investigations were not conducted.

Patient was taken for left inferior parathyroidectomy with right sided cyst excision with intraoperative PTH monitoring with a subsequent need for four gland exploration consequent to non-significant drop in intraoperative PTH. Left inferior parathyroidectomy was done and the specimen was sent for frozen section for confirmation of parathyroid tissue. Right side thyroid and perithyroidal region was

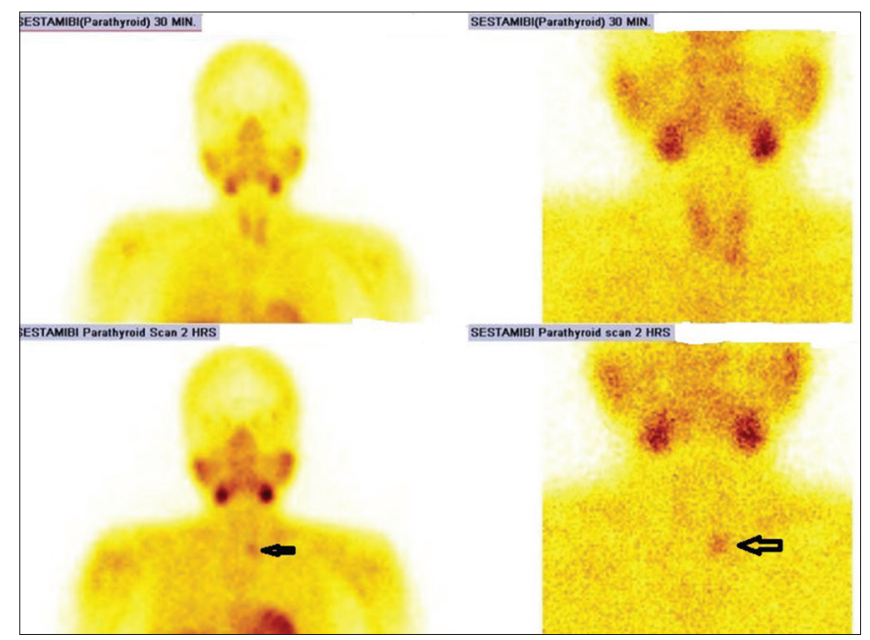

Figure 1: Sestamibi scan showing uptake inferior to left lower pole of thyroid gland suggestive of left inferior parathyroid adenoma explored and a $10 \times 5 \times 6$ mm cystic swelling filled with clear watery liquid was seen adjacent to inferior pole of right thyroid gland. The cyst was not found to be attached to the thyroid or adjacent parathyroid. It was excised atraumatically as the clear watery appearance had triggered the diagnosis of parathyroid cyst and parathyromatosis was a realistic concern. The cyst was sent for frozen section in Toto. Left inferior adenoma was confirmed to be parathyroid tissue on frozen section. However, no definitive opinion could be obtained from the pathologist regarding the right sided cyst on frozen. Intraoperative PTH values were sent and returned satisfactory as per the Miami Criterion ${ }^{[4]}$ after excision of both the lesions.Hence four gland explorations were not done and surgery was terminated. Postoperative calcium and PTH values fell dramatically and rest of the recovery was uneventful. The next day morning PTH was 8.8 and serum calcium was 9.2. Final histopathological examination revealed the left sided lesion to be parathyroid adenoma [Figure 4] and the right sided cystic lesion turned out to be parathyroid cyst. It was composed of parathyroid epithelial cells with stromal fat cells compressed at the periphery of the cyst [Figure 5].

\section{Discussion}

Incidence and clinical presentation.

Parathyroid cysts can be functional or non-functional in nature. These are most commonly found in the fourth to sixth decade. Non-functional cysts are associated with normal serum PTH and calcium levels. They are either picked up when they are large enough to cause pressure symptoms leading to dysphagia, dyspnoea, hoarseness, or as an incidental finding during imaging. Non-functional

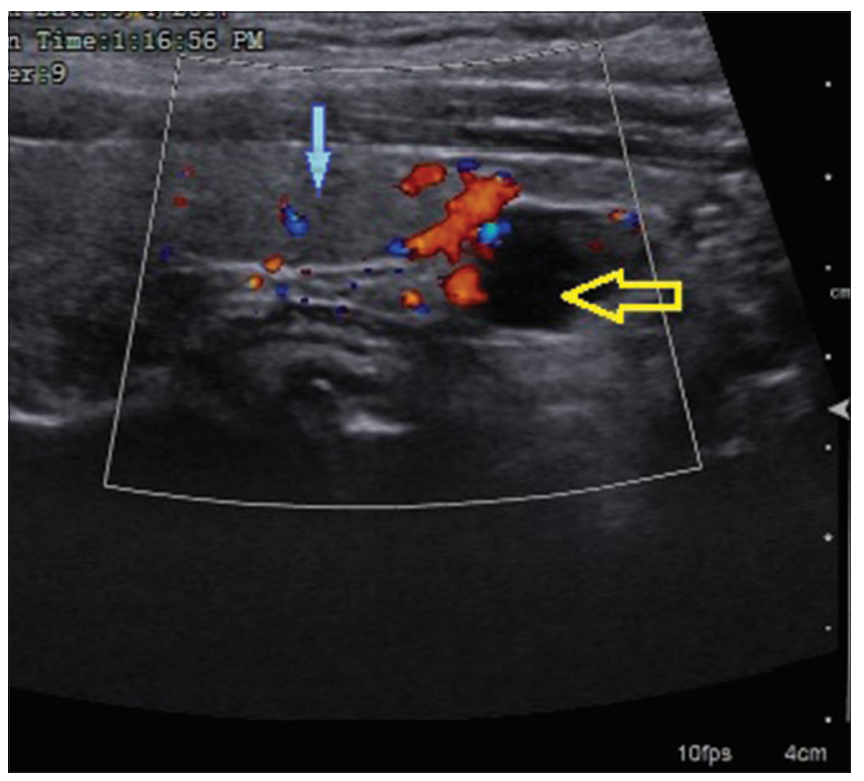

Figure 2: Ultrasound showing well defined, ovoid, hypoechoic lesion $14 \times 8 \times 13 \mathrm{~mm}$ inferior to the inferior pole of left thyroid gland (blue arrow) - parathyroid adenoma (yellow arrow) 


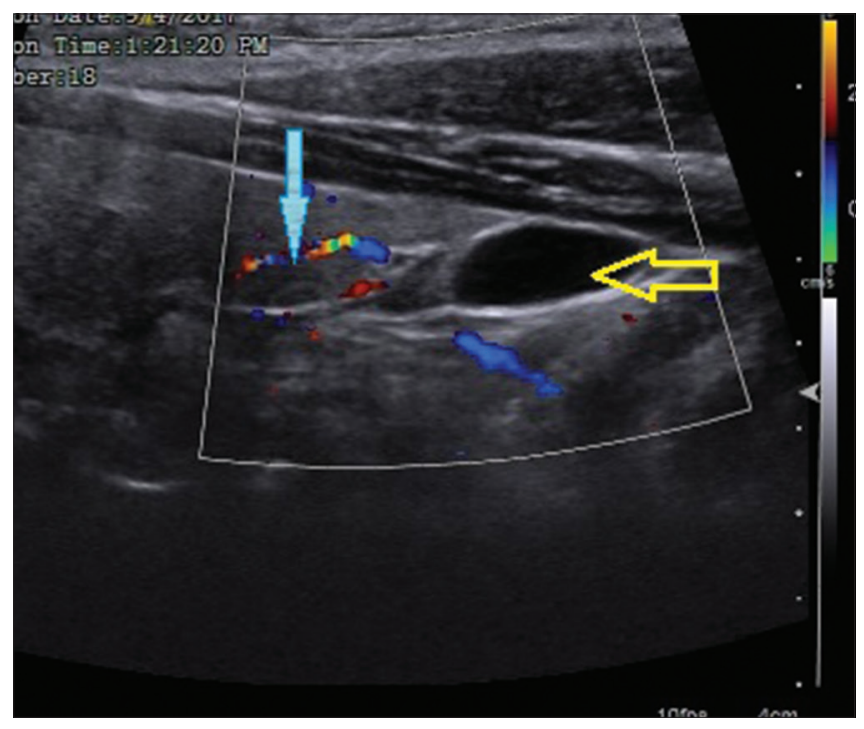

Figure 3: Ultrasound showing hypoechoic, well defined, ovoid cystic nodule measuring $11 \times 8 \times 5 \mathrm{~mm}$ below the lower pole of right thyroid gland (blue arrow) - right inferior cyst (yellow arrow)

cysts are more common in women with a ratio 2.5:1 between females and males. Functional cysts are most often encountered in males with the ratio being 1.6:1 between males and females. ${ }^{[5,6]}$ The functional cysts comprise about $10 \%$ of parathyroid cysts and are associated with clinical and biochemical features of hyperparathyroidism.

The fluid in parathyroid cysts usually contains elevated levels of Carboxy- terminal PTH (inactive form of PTH) and rarely intact - PTH (active form of PTH). ${ }^{[7]}$ Even non-functional cysts can produce large amounts of PTH which rapidly degrades into inactive form of PTH. Hence, measurement of C-terminal PTH is recommended in suspected parathyroid cyst, because measurement of intact PTH in aspirated cyst fluid can often miss the diagnosis of parathyroid cyst. ${ }^{[8]}$ Rarely, parathyroid cysts may also present as hypercalcemic crisis when these cysts rupture leading to discharge of large amounts of parathormone in the bloodstream. ${ }^{[9]}$

In our case, it was difficult to find out whether the cyst was a functional one or non-functional, as the patient had pre-existing hyperparathyroidism, attributable to left inferior parathyroid adenoma. The only way to ascertain the functionality of the cyst would have been if the patient would have had persistent hyperparathyroidism after surgery, in case the cyst would have been completely missed on ultrasound. If the cyst was assumed to be non-functional, then it would have required revision surgery following enlargement of the cyst. Hence in both the cases, revision surgery would have been required eventually. Meticulously performed ultrasound is an effective modality for picking up all abnormal parathyroid tissue, thereby improving surgical success rates and reducing rates of revision surgery.

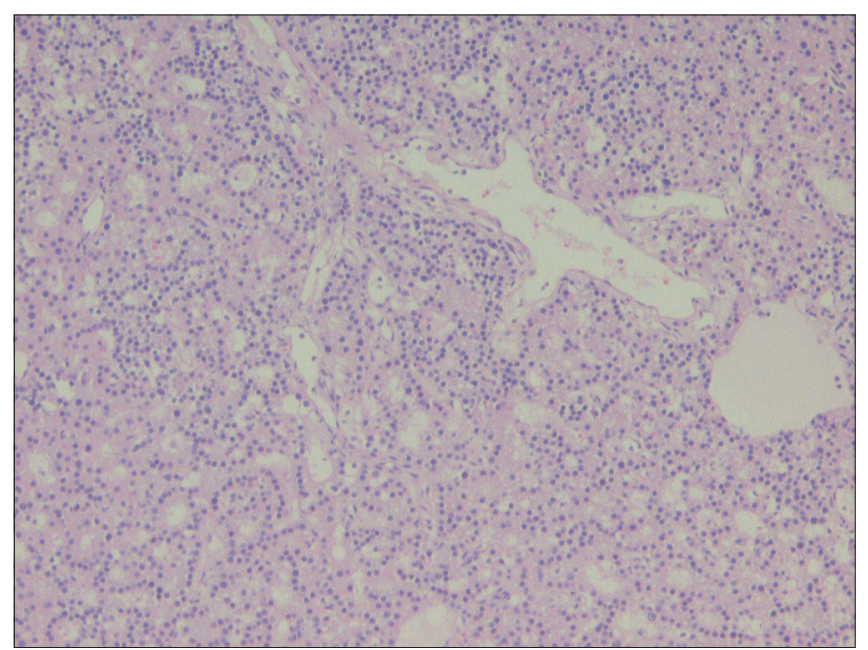

Figure 4: Photomicrograph of parathyroid adenoma showing uniform population of cells

\section{Origin and pathogenesis}

The origin and pathogenesis of these cysts is not clear but a number of theories have been postulated to explain their existence :(a) these cysts may arise from vestigial remnant of the third or fourth brachial cleft or from the persistence of Kürsteiner canals ${ }^{[10]}$;(b) coalescence of parathyroid acini ${ }^{[11]}$; (c) degeneration of parathyroid adenoma ${ }^{[12]}$; (d) retention of secretion vesicles ${ }^{[13]}$; (e) intra-adenoma haemorrhage followed by liquefaction of contents. ${ }^{[9]}$

\section{Investigations}

Imaging is done as part of preoperative preparation and localisation of these cysts. Neck ultrasound is the method of choice, but can rarely differentiate between parathyroid cysts and other cysts of the cervical region like thyroid cysts, thymic cysts, thyroglossal duct cysts, and branchial cleft cysts. ${ }^{[14]}$ Thyroid cysts can be clearly differentiated from other cysts only if they are completely inside the thyroid parenchyma or intrathyroidal. Cysts which are abutting the thyroid or close to the thyroid capsule are often diagnosed as thyroid lesions, though they may be originating elsewhere. These lesions are extremely difficult to differentiate on CT and MRI as well. ${ }^{[15]}$

Ultrasound guided fine needle aspiration and estimation of $\mathrm{C}$ terminal-PTH levels of the aspirated fluid clinch the diagnosis of parathyroid cysts, although cannot differentiate between a functional and non-functional cyst, because even non-functional cysts can produce massive quantities of PTH. ${ }^{[8]}$

Sestamibi scans can diagnose functional cysts at times but are mostly unsuccessful in picking up these cysts because they contain compressed parathyroid tissue at the periphery with reduced number of oxyphil cells. Hence, negative sestamibi scans do not preclude the diagnosis of parathyroid cysts. ${ }^{[16]}$ As in our case, sestamibi scan had 


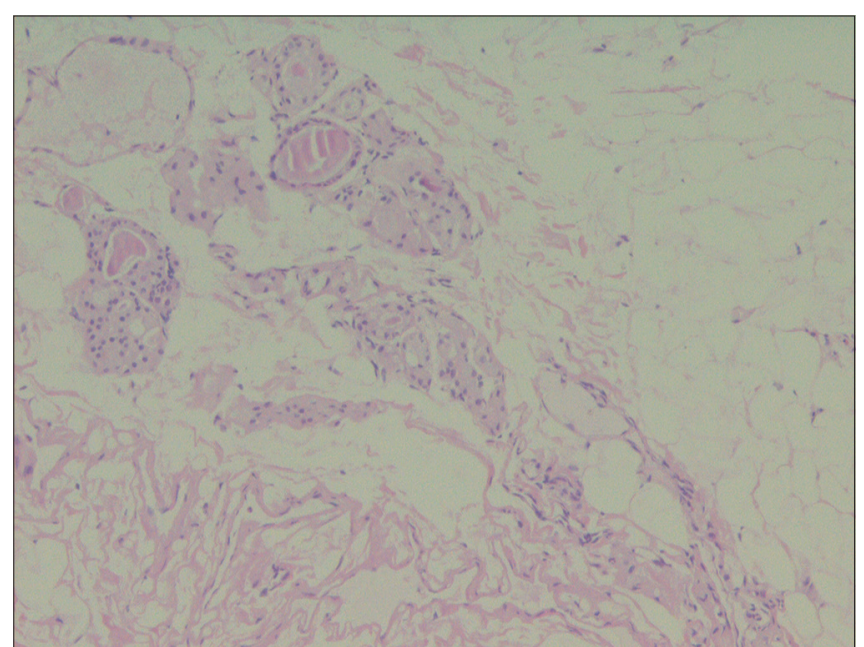

Figure 5: Photomicrograph of parathyroid cyst showing thin rim of compressed parathyroid tissue with cystic areas

only picked the left lateral parathyroid adenoma and had missed the cyst completely. Ultrasound done previously elsewhere had also failed to identify the parathyroid cyst. The only clue to the co-existent parathyroid cyst in our patient was obtained from the repeat ultrasound in our centre. Computed tomography scans (CT) and Magnetic resonance imaging (MRI) can be done to see the relationship of these cysts with adjacent structures but are done generally in cases with large cysts producing pressure symptoms or with significant substernal extension. ${ }^{[15]}$

\section{Treatment}

Parathyroid cysts can be diagnosed preoperatively however, most often than not, these cysts are diagnosed postoperatively based on histopathological findings as happened in the case illustrated above. In cases where the diagnosis arrives preoperatively, the treatment of functional cysts is always surgical excision of the mass. ${ }^{[17]}$ Though malignancy in parathyroid cysts is rare, two cases of parathyroid carcinoma have been reported in the literature in functional cysts previously. ${ }^{[18,19]}$

The treatment of non-functional cysts is controversial. Surgical excision with a clear histopathological diagnosis has been recommended by McCoy et al. even in non-functional cysts as the procedure carries minimal morbidity in experienced hands. ${ }^{[20]}$ Several papers have advocated ultrasound guided aspiration of the fluid, which leads to collapse of the cyst and is considered as the definitive treatment. ${ }^{[21]}$ Treatment with aspiration alone had been considered successful in only one third of the patients with rest of the patients developing a recurrence and requiring re-aspiration later. ${ }^{[22,23]}$

Recurrences following re-aspiration have been dealt with sclerosing therapy with tetracycline and ethanol.
However, this is fraught with complications as the cyst wall is very thin, often only a single layer thick. Hence the chances of leading to cyst rupture and leakage of sclerosing fluid in the pericystic tissues is higher than when used for sclerosis of thyroid cysts which have relatively thicker walls. ${ }^{[2,25]}$ Pericystic fibrosis due to leakage has occasionally been reported to have caused recurrent laryngeal nerve damage and usually leads to escalated morbidity of a surgical procedure, in case of non-resolution of cyst. ${ }^{[26]}$ Hence, surgical excision is the preferred modality of treatment in both functional and non-functional cysts presently.

\section{Conclusion}

Parathyroid cysts are a rare entity. They are often missed on Sestamibi scanning. Anatomical imaging like ultrasound is the modality of choice for picking up these lesions. CT scan and MRI are used to evaluate the relationship of the cyst with adjacent structures, especially in cases of large cysts.Use of adjunct anatomical imaging in conjunction with sestamibi scan minimises the chances of accidentally leaving behind hyperfunctional parathyroid tissue in cases where a coexistent adenoma is present, thus minimising the chances of revision surgery.

\section{Declaration of patient consent}

The authors certify that they have obtained all appropriate patient consent forms. In the form the patient(s) has/have given his/her/their consent for his/her/their images and other clinical information to be reported in the journal. The patients understand that their names and initials will not be published and due efforts will be made to conceal their identity, but anonymity cannot be guaranteed.

\section{Financial support and sponsorship}

Nil.

\section{Conflicts of interest}

There are no conflicts of interest.

\section{References}

1. Cappelli C, Rotondi M, Pirola I, De Martino E, Leporati P, Magri F, et al. Prevalence of parathyroid cysts by neck ultrasound scan in unselected patients. J Endocrinol Invest 2009;32:357-9.

2. Nardi CE, Silva RA, Serafim CM, Dedivitis RA. Nonfunctional parathyroid cyst: Case report. Sao Paulo Med J 2009;127:382-4.

3. Delbridge LW, Younes NA, Guinea AI, Reeve TS, Clifton-Bligh P, Robinson BG. Surgery for primary hyperparathyroidism 1962-1996: Indications and outcomes. Med J Aust 1998;168:153-6.

4. Irvin GL $3^{\text {rd }}$, Solorzano CC, Carneiro DM. Quick intraoperative parathyroid hormone assay: Surgical adjunct to allow limited parathyroidectomy, improve success rate, and predict outcome. World J Surg 2004;28:1287-92.

5. Rosenberg J, Orlando R $3^{\text {rd }}$, Ludwig M, Pyrtek LJ. Parathyroid cysts. Am J Surg 1982;143:473-80.

6. Clark OH. Parathyroid cysts. Am J Surg 1978;135:395-402. 
7. Ippolito G, Palazzo FF, Sebag F, Sierra M, De Micco C, Henry JF.A single-institution 25-year review of true parathyroid cysts. Langenbecks Arch Surg 2006;391:13-8.

8. Lee SL. Parathyroid cyst fluid: Discrepancy between C-terminal and intact parathyroid hormone assays. Thyroid 2000;10:1125-6.

9. El-Housseini $Y$, Hübner M, Boubaker A, Bruegger J, Matter M, Bonny O. Unusual presentations of functional parathyroid cysts: A case series and review of the literature. J Med Case Rep 2017;11:333.

10. Rossi ED, Revelli L, Giustozzi E, Straccia P, Stigliano E, Lombardi $\mathrm{CP}$, et al. Large non-functioning parathyroid cysts: Our institutional experience of a rare entity and a possible pitfall in thyroid cytology. Cytopathology 2015;26:114-21.

11. Pontikides N, Karras S, Kaprara A, Cheva A, Doumas A, Botsios D, et al. Diagnostic and therapeutic review of cystic parathyroid lesions. Hormones (Athens) 2012;11:410-8.

12. Kaplanoglu V, Kaplanoglu H, Cilız DS, Duran S. A rare cystic lesion of the neck: Parathyroid cyst. BMJ Case Rep 2013;2013:bcr2013200813.

13. Calandra DB, Shah KH, Prinz RA, Sullivan H, Hofmann C, Oslapas $\mathrm{R}$, et al. Parathyroid cysts: A report of eleven cases including two associated with hyperparathyroid crisis. Surgery 1983;94:887-92.

14. Ujiki M, Sturgeon C, Nayar R, Angelos P. Parathyroid cyst: Often mistaken for a thyroid cyst. World J Surg 2008;32:1234.

15. Hughes CR, Kanmaz B, Isitman AT, Akansel G, Lawson T, Collier BD. Misleading imaging results in the diagnosis of parathyroid cysts. Clin Nucl Med 1994;19:422-5.
16. Guner A, Karyagar S, Ozkan O, Kece C, Reis E. Parathyroid cyst: The forgotten diagnosis of a neck mass. J Surg Case Rep 2011;2011:4.

17. Goomany A, Rafferty A, Smith I.An unusual neck mass: A case of a parathyroid cyst and review of the literature. Case Rep Surg 2015;2015:243527.

18. Wright JG, Brangle RW. Carcinoma in a parathyroid cyst.IMJ Ill Med J 1985;168:98-100.

19. Pirundini P, Zarif A, Wihbey JG. A rare manifestation of parathyroid carcinoma presenting as a cystic neck mass. Conn Med 1998;62:195-7.

20. McCoy KL, Yim JH, Zuckerbraun BS, Ogilvie JB, Peel RL, Carty SE. Cystic parathyroid lesions: Functional and nonfunctional parathyroid cysts. Arch Surg 2009;144:52-6; discussion 56.

21. DeRaimo AJ, Kane RA, Katz JF, Rolla AP. Parathyroid cyst: Diagnosis by sonography and needle aspiration.AJR Am J Roentgenol 1984;142:1227-8.

22. Prinz RA, Peters JR, Kane JM, Wood J. Needle aspiration of non-functioning parathyroid cysts. Am Surg 1990;56:420-2.

23. Shi B, Guo H, Tang N. Treatment of parathyroid cysts with fine-needle aspiration. Ann Intern Med 1999;131:797-8.

24. Sánchez A, Carretto H. Treatment of a nonfunctioning parathyroid cyst with tetracycline injection. Head Neck 1993;15:263-5.

25. Akel M, Salti I, Azar ST. Successful treatment of parathyroid cyst using ethanol sclerotherapy. Am J Med Sci 1999;317:50-2.

26. Fortson JK, Patel VG, Henderson VJ. Parathyroid cysts: A case report and review of the literature. Laryngoscope 2001;111:1726-8. 